\title{
Computer-Aided Teaching of Math in Electromechanics Vocational Course
}

\author{
http://dx.doi.org/10.3991/ijep.v3iS2.2445
}

\author{
E.S. Hoji ${ }^{1}$, W.B. Vianna ${ }^{2}$ and T.A. Félix ${ }^{3}$ \\ ${ }^{1}$ Federal Institute of São Paulo, Birigui, Brazil \\ 2 Federal University of Santa Catarina, Florianópolis, Brazil \\ ${ }^{3}$ Federal Institute of Brasília, Brasília, Brazil
}

\begin{abstract}
This paper describes the experience of teaching mathematics in the electromechanics vocational course with aid of the computer. Instead of giving a bunch of equations and a calculator to the students, as it is usual in vocational courses, we offer them Octave, which is a numerical computational tool. Furthermore, the mathematical concepts involved in the solution of applied problems are provided within a multidisciplinary framework. The proposed approach helped to reduce the abstraction of mathematics for the students. Despite the deficiencies the students in vocational courses have in their formation, we could notice that their perception regarding mathematics has changed after figuring out that "a bunch of numbers" can be useful in the solution of problems they shall face in their professional life. The approach was applied to three groups already. All of them are composed of mature students, who passed by a flawed basic educational system and stayed away from school for a long time.
\end{abstract}

Keywords - technical education, mathematics teaching, numerical computation, adult education.

\section{INTRODUCTION}

Mathematical thinking [1] is, essentially, a thinking process which comes to abstract ideas logically connected. However, the ability to think mathematically to solve applied problems does not arise suddenly. It depends on the skill to abstractly express problem elements, look at and predict patterns and relationships among them and, finally, empirically find why something is true.

Moreover, there is a gap between basic theoretical requirements to think mathematically and deficiencies in basic and secondary education, which is reflected in the academic life of students in the next levels, whatever in vocational or superior educations. In Brazil, such scenario is worsened by a flawed basic and secondary educational system.

However, it is not a fresh problem. Many studies have been conducted over the time regarding mathematical education in engineering integrating mathematics with computers [2-7], with logical, critical and abstract thinking $[8-11]$ or with other subjects $[12,13]$ in order to make math more attractive to the students.

The situation is even worse in professional education field. In Brazil, the expansion of the federal network of technological education, which is composed of federal institutions that work in technological education field, created over 400,000 places in professional education [14].

The problem is that the most of the students enrolled in professional education are mature and have been passed a long time away from schools or graduated in the secondary level by means of EJA - Educação para Jovens e Adultos (Education for Young and Adults, from portuguese) [15]. EJA is an education form existing in Brazil that aims to provide education levels up to the secondary level to people who are not anymore in schoolage. Thus, students in EJA are usually workers or unemployed who did not have the opportunity to go to school/college at the proper time. Thus, many of them have serious deficiencies regarding basic subjects, including mathematics.

In this paper, we present a computer-aided approach for teaching math to mature students in the electromechanics vocational course. That said, the proposed approach has two main objectives:

1. Make students understand the mathematical concepts they need to solve specific problems and, consequently, improve their interest in math;

2. Provide to students a new tool to solve applied mathematical problems.

To accomplish that, the students are immersed in a multi-disciplinary framework, concerning electricity and mechanics. Then, the mathematical concepts are introduced to students as needed to solve applied problems.

In order to improve their attention and render the solution achievement interesting, the students can have the help of Octave [16] to solve the problems. The Octave is a high-level interpreted language, primarily intended for numerical computations and is quite similar to Matlab. It provides capabilities for the numerical solution of linear and nonlinear problems, and for performing other numerical experiments.

Also, Octave is an open-source software, which allows students to download it and practice at home. Any other calculations software might be used to support the students, such as Scilab or Freemat.

Using numerical computation software has proved to be an effective tool to improve student interest in mathematics. Students claim that using Octave makes solving mathematical problems easier and allows them to visualize how a "bunch of numbers" can be useful, which 
makes mathematics more interesting, as we describe in the following sections.

\section{COMPUTER-AIDED APPROACH}

In the professional education field, students' formation is orientated towards craft more than theory. However, proposing solutions or improvements to processes are also among the prerogatives of technicians. So, mathematics is also necessary to their professional life in some depth.

In this methodology, mathematics is integrated with applied subjects concerning electricity or mechanic fields. Therefore, mathematical concepts are taught "on-demand" within the proposed framework, as they are needed to solve problems.

Since Math is being treated as a tool, some aspects may be adjusted during the course, according to students' needs. Such adjustments have to take into account students' achievements in the disciplines and their feedback regarding the methodology.

\section{A. Solution Achievement}

When dealing with mature students, we must consider that their cognitive skills have been reduced due to many factors, such as age, the long time away from school and the lack of practicing. In this regard, the use of Octave as a solver aims to reduce the abstraction of mathematics and allows the students to realize what it can be used for. Moreover, they can study math focusing on its application and not worrying about the calculations they need to do.

Nevertheless, we do not neglect the math fundamental concepts involved in the solution of the problems. Instead, we show students that any problem can be expressed in numbers.

Therefore, the first step students need to proceed to find the solution of a problem is to structure it mathematically. To accomplish that, they have to identify which technical concepts are involved in the solution and how the problem can be described mathematically. This is a very important step, which might help them to improve their logical thinking and their organizational skills, and is crucial for the solution of the problem.

After that, the set of equations that describes the problem is defined, and the necessary mathematical concepts to achieve the solution are introduced to the students. At this point, the students are encouraged to solve the problem by two different ways:

1. To achieve the hand-made solution, the students have to apply the mathematical concepts and perform all the necessary calculations by themselves. This step aims to force the students to memorize the mathematical concepts and to develop their concentration and organizational skills.

2. The computer-aided solution is obtained with the help of Octave. The students have to "present" the mathematical problem they formulated in the former step to the computer. Thus, at this step, logical skills and knowledge of programming language and structure can be addressed.

To proceed with the solution of the problems, students have to learn how to use Octave. The commands they need to know are gradually introduced, as well as the mathematical concepts.

Finally, both solutions can be compared and tested in the original problem in order to validate them. Gradually, as the students get more confident, they are allowed to pass hand-made solution by. Therefore, the solution of math problems is basically composed by three steps, as shown in the Fig. 1.

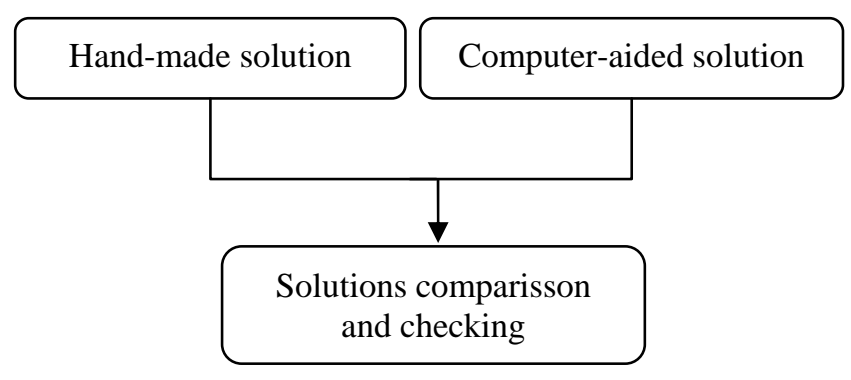

Figure 1 - Steps for the solution achievement.

\section{B. Student Assessment}

Students' progresses are assessed by a mix of continuous assessment and regular tests. The combination of these evaluation criteria allows identifying students' weaknesses regarding each issue and, also, evaluate their capability of connecting the concepts addressed during the course in order to solve applied problems.

The continuous assessment activities help to memorize the mathematical concepts and their applications. It comprises frequency, participation, commitment and development of the students and it aims to stimulate them to take part in the proposed activities, which include tasks such as practices, exercises, seminars and some extra activities with a monitor, who is chosen among the group by the colleagues. During these activities, students are invited to solve the problem in the blackboard and they are allowed to use the computer, including researches on the Internet about the subject. Also, during such activities, students practice with Octave, which help them to get more skilled with the software.

The knowledge students acquire and their capability to connect the former addressed above are assessed with two tests. In each test, they have to solve applied problems regarding the disciplines integrated with the math course, e.g., compute the currents which flow in an electric circuit, determine the resultant force-torque acting on a mechanical coupling or calculate the amount of building material necessary to craft a piece.

The first test takes place at the middle of the course. Initially, only the hand-made solution was requested in this test. Despite the fact that students use Octave since the beginning of the course, at this point we were concerned to verify their organizational skills and logical thinking by means of their capability of structure the problems. Nevertheless, the achievement of students in the first group evaluated suggested that some changes regarding the assessment criteria would be welcome, as explained in section III. 
At the end of the course, students take a second test, in which they have to calculate both hand-made and computer-aided solutions. At this point, students must be able to structure and solve the problems by using any method they have learned during the course.

The final score is composed of a weighted average of the scores obtained by the student in the tests and in the continuous assessment activities, as expressed by (1). For each activity, the maximum score to be obtained is 10.0 . The minimum final score for approval is 5.0:

$$
\mathrm{FS}=\mathrm{w}_{\mathrm{E} 1} * \mathrm{E} 1+\mathrm{w}_{\mathrm{E} 2} * \mathrm{E} 2+\mathrm{w}_{\mathrm{CA}} * \mathrm{CA}
$$

In which:

$$
\begin{array}{lll}
\text { FS } & - & \text { Final Score; } \\
\mathrm{E} 1 \quad- & \text { First test score; } \\
\mathrm{E} 2 \quad- & \text { Second test score; } \\
\mathrm{CA} & -\quad \text { Continuous Assessment score. } \\
0.0<\mathrm{w}_{\mathrm{E} 1}, \mathrm{w}_{\mathrm{E} 2}, \mathrm{w}_{\mathrm{CA}}<1.0 \\
\mathrm{w}_{\mathrm{E} 1}+\mathrm{w}_{\mathrm{E} 2}+\mathrm{w}_{\mathrm{CA}}=1.0
\end{array}
$$

The weights in (1) can be defined according to the teaching plan and in order to encourage the students to finish the course, by allowing the students to approve in the discipline even if they do not get high scores at the first test and in the continuous assessment tasks. We emphasize that many students evade the course when they get low scores in the $1^{\text {st }}$ test.

\section{STUDENTS’ ACHIEVEMENT}

The computer-aided approach described above is currently being applied in the first module of the electromechanics vocational course, which comprises the basic subjects, such as math. The flowchart of the course is shown in Fig. 2. The electromechanics vocational course is composed of four sequential modules, with a total workload of 1380 hours plus a minimum of 160 hours of supervised practical activities.

Each module, except the first, is concerned with a specific field of electromechanics. If a student succeeds in all subjects in a module, he gets an intermediate professional certification that enables him for some functions in the labor market. After concluding all the modules and the internship, students get a diploma in electromechanics technician.

Three groups have been evaluated yet. The number of students enrolled in each group and the dropout rates are shown in Table 1. In this paper, we focus on computeraided approach for teaching math. Therefore, we consider only the students who finished the basic module of the course. A detailed study about the drop out levels and the programs developed at Federal Institute of Brasilia to improve retention can be found in [17].

TABLE I. STUDENT ENROLLMENT AND DROPOUT.

\begin{tabular}{|c|c|c|c|c|}
\hline Group & $\begin{array}{c}\text { Year of } \\
\text { enrollment }\end{array}$ & $\begin{array}{c}\text { Students } \\
\text { enrolled }\end{array}$ & $\begin{array}{c}\text { Students } \\
\text { dropout }\end{array}$ & $\begin{array}{c}\text { Students } \\
\text { evaluated }\end{array}$ \\
\hline A & 2011 & 39 & 14 & $\mathbf{2 5}$ \\
\hline B & 2012 & 35 & 12 & $\mathbf{2 3}$ \\
\hline C & 2012 & 35 & 14 & $\mathbf{2 1}$ \\
\hline
\end{tabular}

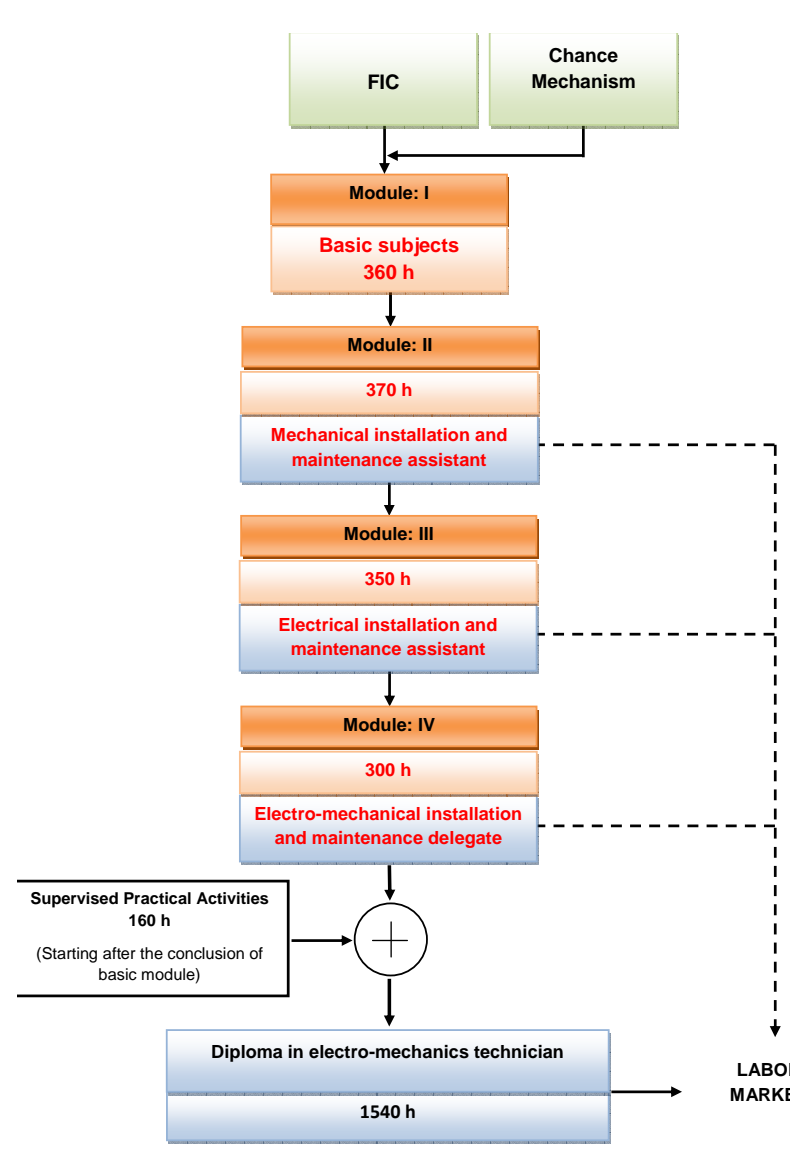

Figure 2 - Flowchart of the electro-mechanical technical course.

The group A was the first with students who passed by an introductory course [17] and the first one enrolled under this methodology. So, students in group A provided us many indications about which aspects might be improved in the methodology and such improvements were considered with groups $\mathrm{B}$ and $\mathrm{C}$. Therefore, $\mathrm{a}$ detailed analysis regarding group $\mathrm{A}$ is presented in advance, in order to put the improvements carried out with groups $\mathrm{B}$ and $\mathrm{C}$ on a basis.

However, the deficiencies that students bring from secondary level can be noticed in all the groups, denoted by the lack of basic mathematical knowledge and logical thinking. It constitutes a great challenge in professional education level, which is worsened by the lack of a selection process of the students enrolled [17].

\section{A. Group A assessment}

The continuous assessment activities constitute a fundamental part of the approach when dealing with mature students. Through them, we can evaluate students' commitment and progress, identify their weaknesses, and propose new activities, based on what we realize.

To understand further aspects and criteria of the continuous assessment that is being applied, we are going to present a detailed analysis regarding group A. For this group, continuous assessment activities were split into three groups according to the subject and which are sequentially applied, as follows:

Activity group 1: basic algebra, matrices and linear systems. 
Activity group 2: complex numbers.

Activity group 3: vectors, forces and torques and geometry.

The students developed extra activities regarding each topic above. In such activities, students were encouraged to solve exercises about the current topic and practice with Octave. Besides their achievement, participation and commitment, students are evaluated during the extra activities by means of frequency and oral questions.

A monitor helped students during the extra activities. He was chosen between the students in the group due to his achievement in the class activities and earns a scholarship during his tenure.

The average scores got by the students in group A for each activity group are presented in Table 2. One can realize that their average performance was improved over time, as they got more skilled with Octave. Also, the average frequency in the extra activities was close to 85\%, which can be considered high if we take into account that all the students enrolled have a job.

The final continuous assessment score (CA) in (1) is determined by the average of the scores obtained in each activity group and the frequency in extra activities.

TABLE II. AVERAgE STUDENTS’ ACHIEVEMENT IN THE CONTINUOUS ASSESSMENT TASKS - GROUP A.

\begin{tabular}{|c|c|}
\hline Task & Average score \\
\hline Frequency (extra activities only) & $82.5 \%$ \\
\hline Activity group 1 & 3.0 \\
\hline Activity group 2 & 5.1 \\
\hline Activity group 3 & 5.4 \\
\hline CA & $\mathbf{5 . 4}$ \\
\hline
\end{tabular}

Besides the continuous assessment, two tests are applied to evaluate the use of Octave. Likewise the continuous assessment activities, the regular tests applied to group A provided important information about the efficacy of the method.

Students in such group answered the first test twice. Initially, they were not allowed to use any kind of solver, neither a calculator. Then, they were allowed to use Octave to help in the solution achievement process. Fig. 3 illustrates the distribution of the scores obtained by the students in both situations and the accumulative \% of students according to their scores.

Without the help of Octave, the average score of the group was 3.8 and only slightly more than $30 \%$ of the students got a score over the minimum of 5.0. Due to the low performance of the group, we let them make the $1^{\text {st }}$ test once more, with the aid of the Octave.

When aided by the computer, the average score of the group was 5.4 and over $50 \%$ of the students reached the minimum of 5.0. In addition to that, the scores obtained by the students were more uniform, concentrating in the rate between 5.0 and 7.0.

The substantial improvement on student achievement when aided by Octave led us to allow the students to use the software in any activity until the end of the course.

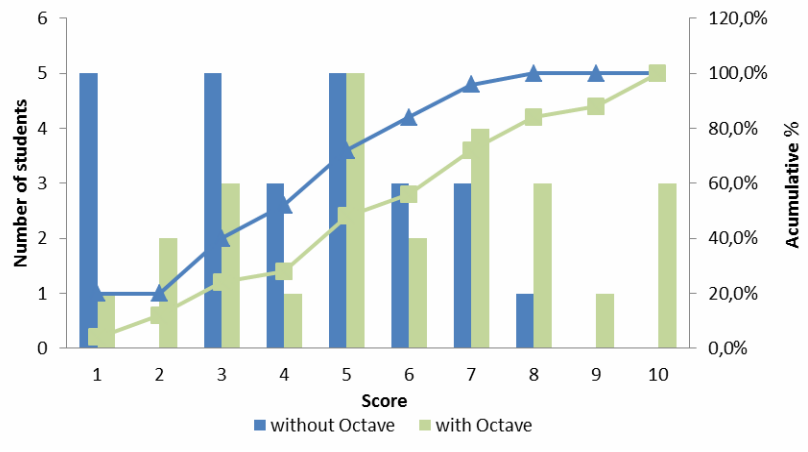

Figure 3 - Distribution of the scores obtained by the students from group $\mathrm{A}$ in the 1 st test.

The second test was applied to group A only once and students could have the help of the software. The average score of the group was 5.5 and over $70 \%$ of the students reached the minimum score. The distribution of the scores obtained by the students from group $\mathrm{A}$ in the $2^{\text {nd }}$ test is shown in Fig. 4.

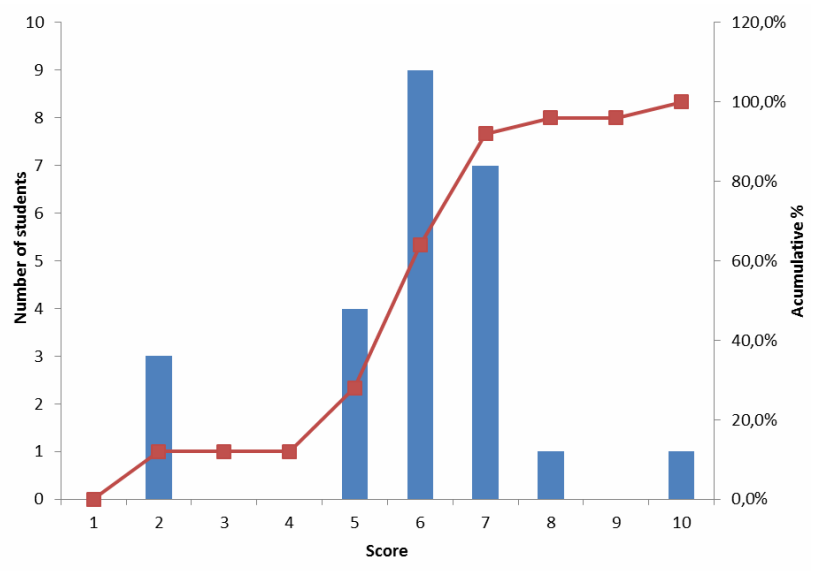

Figure 4 - Distribution of the scores obtained by the students from group $\mathrm{A}$ in the 2nd test.

Students' approval is determined by their final score, calculated by (1). Since it's a new proposal for teaching mathematics, the weights for each activity are currently being determined in an empiric basis, according to the teaching plan and in order to stimulate the students. For group $A$, we considered the following weights in (1): wE1 $=0.3$; $\mathrm{wE} 2=0.5$ and $\mathrm{wCA}=0.2$.

Fig. 5 shows the distribution of the final scores, determined by (1). A total of 8 students didn't get the minimum score of 5.0, among which 4 have been evaded the course.

Despite the overvaluation of the $2^{\text {nd }}$ test, in which students achieved higher scores, the failure rate in group A was over $30 \%$. We recognize it is high, but we have to take into account that we are dealing with mature students who have serious deficiencies in math and logical thinking. Also, it was the first group enrolled under this methodology. 


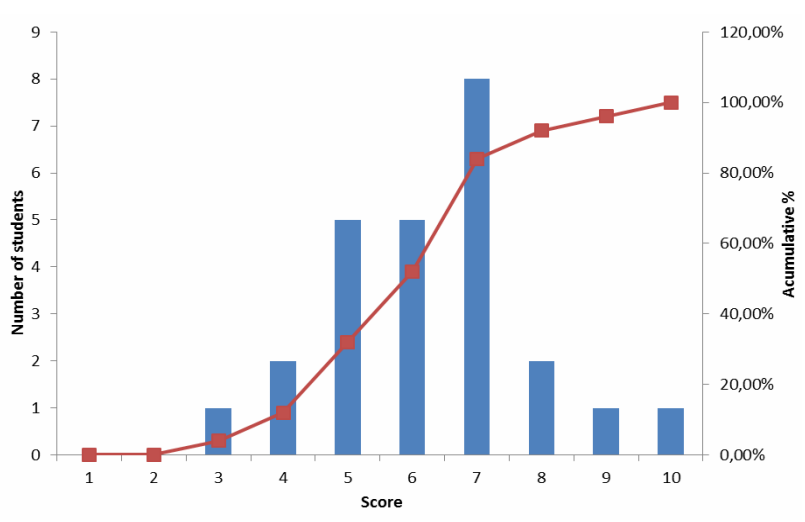

Figure 5 - Distribution of the final scores obtained by the students from group A.

\section{1) Students' feedback}

Once students in group A were the first enrolled under the proposed methodology, they were invited to provide us a feedback about this learning experience. They answered a simple inquire about the method, in which they pointed out the highlights and drawbacks of the approach according to them. Their answers are shown in table 3. 19 out of 25 students in the group provided the feedback.

For the most of them, using Octave makes solving mathematical problems easier and allows visualizing how a "bunch of numbers" can be useful to solve applied problems they shall face in their professional life. According to them, it makes mathematics more interesting.

Students also claimed that the approach might help them to recover part of the deficiencies they carry from basic and secondary education. However, they complained that more time should be dedicated to the use of the software and it will be intensified during the following modules of the course. Moreover, many of them claim that the performed activities were not enough to learn how to use the software.

Nevertheless, the major drawback pointed out by students was their lack of ability to deal with the computer, especially within a programming environment, in which there is a bunch of commands to be memorized.

TABLE III. STUDENTS’ FEEDBACK - GROUP A

\begin{tabular}{|l|c|c|}
\hline \multicolumn{1}{|c|}{ Question } & Yes & No \\
\hline $\begin{array}{l}\text { Do you think the use of Octave was } \\
\text { valid? }\end{array}$ & 19 & 0 \\
\hline $\begin{array}{l}\text { Did it help to improve your interest on } \\
\text { math? }\end{array}$ & 16 & 3 \\
\hline Did you find any difficult to use it? & 19 & 0 \\
\hline $\begin{array}{l}\text { The performed activities were enough to } \\
\text { practice? }\end{array}$ & 8 & 11 \\
\hline $\begin{array}{l}\text { Would you like to keep using Octave } \\
\text { during the course? }\end{array}$ & 19 & 0 \\
\hline $\begin{array}{l}\text { Do you think that using Octave in high } \\
\text { school education would help students to } \\
\text { understand math in that level? }\end{array}$ & 17 & 2 \\
\hline
\end{tabular}

\section{B. Groups B and C assessment}

Based on the achievements and on the feedback provided by students in the group A, some improvements have been considered in the methodology for the next groups:

- The number of extra activities was increased, once it demonstrated to improve the commitment and the progress of the students. Also, in order to stimulate the students to participate in the extra activities, the weights in (1) were updated to $\mathrm{w}_{1}=0.35 ; \mathrm{w}_{2}=0.35$ and $\mathrm{w}_{3}=0.30$;

- Since student achievement was improved with the use of Octave, it has become more intense, being allowed in every activity;

- Finally, the disciplines of technical drawing and machine element were integrated to the multidisciplinary framework for teaching math. It allowed the learning of additional mathematical concepts, which were not covered in the initial framework. Therefore, the topics were shared into slightly different activity groups for groups $\mathrm{B}$ and $\mathrm{C}$.

The average scores for each assessment activity and the final score by group are shown in Table 4 . For the sake of comparison, the average score considered for E1 in group A was that obtained with the help of Octave.

TABLE IV. AVERAge STUdENTS’ ACHIEVEMENT In GRoups A, B AND C FOR EACH ASSESSMENT ACTIVITY.

\begin{tabular}{|c|c|c|c|c|c|}
\hline \multirow{2}{*}{ Group } & \multicolumn{4}{|c|}{ Average score } & Students \\
\cline { 2 - 5 } & E1 & E2 & CA & FS & succeed \\
\hline A & 5.4 & 5.9 & 5.4 & 5.7 & $17(68 \%)$ \\
\hline B & 7.8 & 7.1 & 8.3 & 7.7 & $16(70 \%)$ \\
\hline C & 5.8 & 6.6 & 6.8 & 6.4 & $14(67 \%)$ \\
\hline
\end{tabular}

One can notice that the improvements adopted with groups $\mathrm{B}$ and $\mathrm{C}$ turned out to better student achievement. The average performances of students in both groups were greater than those students in group A, especially in the $1^{\text {st }}$ test. Despite that, the percentages of succeeded students in each group were close to $70 \%$.

An in depth analysis can be carried out from Fig. 6, which illustrates the distribution of the final scores obtained by the students in the groups A, B and C. While the final scores obtained by the students in groups $\mathrm{A}$ and $\mathrm{C}$ are concentrated around 7.0, for group $\mathrm{B}$ it is around 9.0.

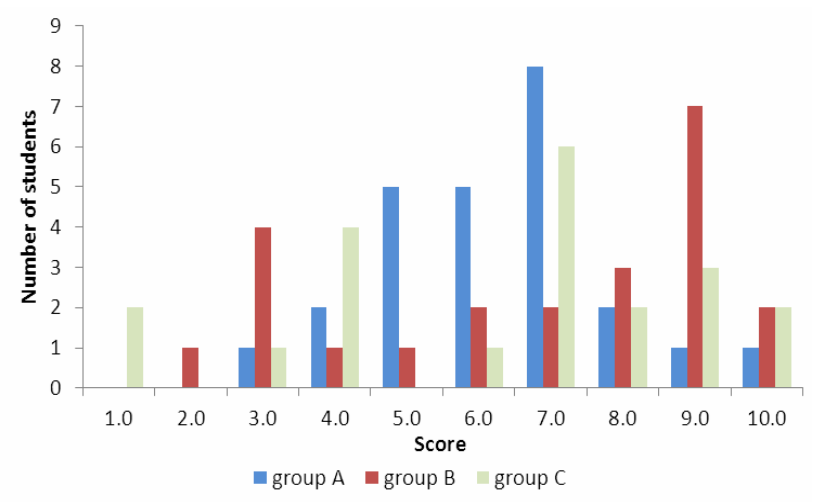

Figure 6 - Distribution of the final scores obtained by the students. 
Such pronounced difference in the performances of groups $\mathrm{B}$ and $\mathrm{C}$, which have been enrolled at the same time, is because part of the students in group $B$ have passed by the introductory course, while the whole group $\mathrm{C}$ realized through the chance mechanism [17].

During the classes, we realized that using Octave was easier to the students who have passed through the introductory FIC course. Therefore, we can say that the improvement on individual performance afforded by the use of Octave is proportional to the knowledge of basic mathematical concepts, i.e., the computers do not solve deficiencies students bring from basic school, but it helps them to understand new mathematical concepts and their applications.

\section{Students' feedback}

As for students in group A, the students in groups B and $\mathrm{C}$ were invited to provide us a feedback about this learning experience. They answered a simple form about the method, in which they pointed out the highlights and drawbacks of the approach according to their opinion. Their answers are shown in Table V. Unfortunately, not all the students answered it again.

The opinion of students in groups $\mathrm{B}$ and $\mathrm{C}$ about the use of Octave is similar to the group A students'. For most of them, using Octave was a valid experience, since it makes easier to solve mathematical problems, but increasing the discipline workload is necessary.

Furthermore, they claim that it would be interesting to apply the methodology within a practical framework, such as during laboratory activities or in the development of a project.

TABLE V. STUDENTS’ FEEDBACK - GROUPS B AND C

\begin{tabular}{|l|c|c|}
\hline \multicolumn{1}{|c|}{ Question } & Yes & No \\
\hline $\begin{array}{c}\text { Do you think the use of Octave was } \\
\text { valid? }\end{array}$ & 15 & 2 \\
\hline $\begin{array}{l}\text { Did it help to improve your interest on } \\
\text { math? }\end{array}$ & 13 & 4 \\
\hline Did you find any difficult to use it? & 8 & 9 \\
\hline $\begin{array}{l}\text { The performed activities were enough } \\
\text { to practice? }\end{array}$ & 8 & 9 \\
\hline $\begin{array}{l}\text { Would you like to keep using Octave } \\
\text { during the course? }\end{array}$ & 16 & 1 \\
\hline
\end{tabular}

\section{DISCUSSION}

The presented experience goes against the traditional way to teach math in vocational courses. Instead of giving a bunch of formulas, values and a calculator to the students, we are introducing new tools and mathematical concepts involved in the solution.

More than just improving scores, we could notice that our method makes students got enthusiastic regarding math. The "applicability" of math to practical problems is getting their attention and discovering such a "powerful calculator" is stimulating them to understand the necessary concepts to structure the mathematical problems, since finding the solution is now much easier.

The fact that mathematical contents are cumulative allows the practice during the whole course. So, students can repeatedly use the mathematics skills they studied. The repetition of processes helps the students to memorize the concepts, especially the basic ones. In this way, the continuous assessment activities provide important information about students' progress and improve their commitment.

An interesting fact is that students get more excited when they can use Octave and they try to structure the problem harder than only the hand-made solution is allowed. So, the interest for the software is a key factor to the improvement of their achievements.

Nevertheless, some features need to be improved in the methodology. We noticed it is important to adapt disciplines workloads according to the integrated disciplines, since learning a technical subject and mathematics at the same time causes students to have a lot of contents addressed simultaneously.

Furthermore, the lack of basic mathematical knowledge and logical thinking is a great challenge faced in vocational courses. For that reason, we believe that students' claim for a greater workload dedicated to mathematics in the course is valid. This problem could be partially solved by the introductory FIC course, as demonstrated with groups $\mathrm{B}$ and $\mathrm{C}$. The students who passed through the FIC achieved better results.

Another feature that needs attention is the integration between different disciplines. It demands the collaboration between professors of the disciplines and the synchronization of the contents, which is not an obvious task.

Until now, the successfully integration between technical disciplines with math was possible because the same professor taught both of them. That could be an alternative, but the problem would lie on the professor's formation. It would be necessary an engineering that likes to teach math or a mathematician interested by a technical field.

Following what the students proposed, a more practical environment could be created for the application of the methodology. In this regard, a project-based learning (PBL) framework would be an interesting alternative.

Finally, we have to consider that it is harder for mature students to remove the rust and get the hang of mathematics and computers. Therefore, we first need to update and organize their thinking structure.

To accomplish that, more efforts should be addressed to improve their logical thinking and reading comprehension skills. In many cases they could not understand the activities and their answers were a mess. In this regard, some activities to address these topics would be welcome to the methodology.

\section{CONCLUSIONS}

Despite the improvements on student achievements, prior deficiencies in students' formation are not completed healed by the introductory FIC course. Moreover, not all students in the vocational course on electromechanics have passed through the FIC. In this regard, new teaching methodologies must be developed in order to attend specific groups.

Developing mathematical applications to practical problems shows to be an effective way to improve students' interest in math. Also, using numerical 
computation software stimulates them to understand the necessary concepts to structure mathematical problems.

Using numerical computational tools, such as Octave, presents a new horizon regarding math to the students in the electromechanics vocational course and make them more enthusiastic about mathematics.

However, some further weaknesses of the students were identified, such as the lack of logical thinking and reading comprehension. In this regard, a study support program is being structured as a further device to help the students.

\section{REFERENCES}

[1] C. F. Medeiros, "Modelos mentais e metáforas na resolução de problemas matemáticos verbais," Revista Ciência e Educação, vol. 7, pp. 209-234, 2001.

[2] G. L. de la Barra, A. M. Urbina, and M. L. de la Barra, "Computer lab in maths courses," in Frontiers in Education, 2002. FIE 2002. 32nd Annual, 2002, pp. S4A-7 vol.3.

[3] J. R. S. Fonseca, "On The contribution of using computers in the classroom in teaching/learning statistics," in Frontiers In Education Conference - Global Engineering: Knowledge Without Borders, Opportunities Without Passports, 2007. FIE '07. 37th Annual, 2007, pp. F3J-7-F3J-12.

[4] H. Gu and W. Zhang, "An experimental study of college teaching based on Matlab software," in Intelligent Computation Technology and Automation (ICICTA), 2012 Fifth International Conference on, 2012, pp. 69-71.

[5] J. Hanc, S. Lukac, J. Sekerak, and D. Sveda, "Geogebra \&\#x2014; A complex digital tool for highly effective math and science teaching," in Emerging eLearning Technologies and Applications (ICETA), 2011 9th International Conference on, pp. 131-136.

[6] P. Kajetanowicz and J. Wierzejewski, "Combining various technologies in effective online math instruction - a nationwide secondary level math project," in Interactive Collaborative Learning (ICL), 2011 14th International Conference on, 2011, pp. 386-389.

[7] Y. Phillips, "The use of technology in mathematics education," in Education Technology and Computer (ICETC), 2010 2nd International Conference on, 2010, pp. V1-499-V1-503.

[8] J. Bohorquez and C. Rocha, "Towards the effective use of formal logic in the teaching of discrete math," in Information Technology Based Higher Education and Training, 2005. ITHET 2005. 6th International Conference on, 2005, pp. S3C/1-S3C/8.

[9] I. Casas, P. S. Goodman, and E. Pelaez, "On the Design and Use of a Cognitive Tutoring System in the Math Classroom," in Technology for Education (T4E), 2011 IEEE International Conference on, pp. 9-17.

[10] K. McMaster, B. Rague, and N. Anderson, "Integrating Mathematical Thinking, Abstract Thinking, and Computational Thinking," in Frontiers in Education Conference (FIE), 2010 IEEE, 2010, pp. S3G-1-S3G-6.

[11] N. M. Radzi, M. S. Abu, and S. Mohamad, "Math-oriented critical thinking skills in engineering," in Engineering Education (ICEED), 2009 International Conference on, 2009, pp. 212-218.

[12] R. N. Laoulache, N. A. Pendergrass, R. J. Crawford, and R. E. Kowalczyk, "Integrating engineering courses with calculus and physics to motivate learning of fundamental concepts," in Frontiers in Education Conference, 2001. 31st Annual, 2001, pp. F1B-13-18 vol.2.

[13] A. Manacero, Jr. and N. Marranghello, "Turning math attractive to computer science students: an application-to-model approach," in Frontiers in Education Conference, 1999. FIE '99. 29th Annual, 1999, pp. 11B3/24-11B3/29 vol.1.

[14] BRASIL, "Expansão da Rede Federal de Educação Profissional, Científica e Tecnológica," Ministry Of Education. Available: http://redefederal.mec.gov.br

[15] BRASIL, "Ordinary Law no. 9.394/1996," in Diário Oficial [da República Federativa do Brasil], ed, Dec. 23, 1996, p. 27833. [Online]. Available: http://www.in.gov.br/in (in Portuguese). .

[16] Available: <http://www.gnu.org/software/octave/>.

[17] E. S. Hoji, W. B. Vianna, and L. M. Leodido, "A formative itinerary model for access to technical courses - the FIC experience," in 15th International Conference on Interactive Collaborative Learning (ICL), Villach, Austria, 2012. http://dx.doi.org/10.1109/ICL.2012.6402122

\section{AUTHORS}

E. S. Hoji received the B.S. degree in electrical engineering, M.Sc., and Ph.D. degrees from the UNESPIlha Solteira, Brazil, in 2004, 2006, and 2011, respectively. In 2007 he was a Visiting Researcher with the University of Castilla-La Mancha, Ciudad Real, Spain. His main interests are in power systems analysis, operation, and control and engineering education. He was with Federal Institute of Brasília, Taguatinga, DF 72146000 Brazil. Currently, he is with Federal Institute of São Paulo, Birigui, SP 16201-407 Brazil (e-mail: es_hoji@ieee.org).

W. B. Vianna received the M.Sc., and Ph.D. degrees in Production Engineering at Federal University of Santa Catarina - UFSC, Brazil, in 2008 and 2011, respectively. He was with Federal Institute of Brasília, Taguatinga, DF 72146-000 Brazil. Now, he is with Federal University of Santa Catarina, Florianópolis, SC 88.036-570 Brazil. His main interests include quality management, multicriteria decision theory, performance assessment and information science. (e-mail: wpwilliam@hotmail.com).

T. A. Félix received the Electrical Engineer degree at Federal University of Campina Grande - UFCG, Brazil. She is currently with Federal Institute of Brasília, DF 72146-000 Brazil. Her research interests include electricity markets and power systems computations, economics, and engineering education. (e-mail: taisa.felix@ifb.edu.br).

This article is an extended and modified version of a paper presented at the International Conference on Engineering Pedagogy (IGIP2012), held 26 - 28 September 2012, in Villach, Austria. Received 15 December 2012. Published as resubmitted by the authors 27 February 2013. 